\title{
Children's Shared Understanding of Media Marketing As A Step Towards Developmentally Appropriate Media Literacy
}

\author{
Lyse Anne LeBlanc \\ Mount Saint Vincent University
}

\begin{abstract}
Media marketing is ubiquitous in nature. In Western societies, where contemporary digital and electronic media forms and the marketing messages they disseminate are primary social and cultural influences, it is crucial that educators have a solid understanding of children's developmental ability to interpret and engage critically with media forms. Theory of Mind [ToM] is the ability to understand the mental states and intentions of others and ourselves [1] [2] [3] [4]. If we consider that the development of a mature ToM enables individuals to explain, predict, and manage others' behaviours, and is considered to be an integral component for developing the ability to reason logically and abstractly, it seems both logical and plausible to consider it in relation to the necessary skills towards thinking critically about media [5]. This doctoral dissertation will demonstrate the need for a better understanding of how children perceive the mass media world that surrounds them. Through an examination of the contextual relationship between Theory of Mind and media literacy, this innovative research study in progress will provide a unique contribution to the fields of both education and psychology, as well as the broader digital economy, in its production of knowledge about and for children's understanding and well being. Children's expressed media understandings will provide the developmental basis for exploring the developmental appropriateness of school-age media literacy curricula.
\end{abstract}

\section{Introduction}

More than ever, there is an urgent need to turn off the television set, Internet and cell phone and talk about a marketer's nightmare... children who can think critically about the media world in which they are surrounded. This is a topic of study that requires constant review and persistence to be kept abreast of the continually expanding media world.

Media marketing is ubiquitous in nature. Comstock \& Sharrer share results of the Committee on Communications from the American Academy of Pediatrics, which state that children and adolescents view 40000 ads per year on TV alone [6]. This statement, coupled with results form a study by
Batada \& Borzekowski that concluded that while the participants are familiar with television commercials, "children as old as 10 years may not understand the persuasive nature of television food advertising directed to children," is troublesome on so many levels [7]. The "cradle-to-grave consumerism' approach has become entrenched within our society and children are increasingly saying 'I want that, and that...' because advertising and other social messages tell them they need it, in order to fit in with their peers [8]. Meanwhile, advertisers tap into 'the nag factor' in an attempt to get children to guilt parents into buying their product [9].

Today advertising goes far beyond television viewing and is infiltrated into our everyday experiences through personal media devices and internet usage, whereby marketers target specific individuals through online data, and even build marketing campaigns that encourage consumers to 'share' their products online [10]. As childhood goes increasingly 'online', researchers need to step back and recognize the power media have, how it is portrayed in our society, and how it is investigated.

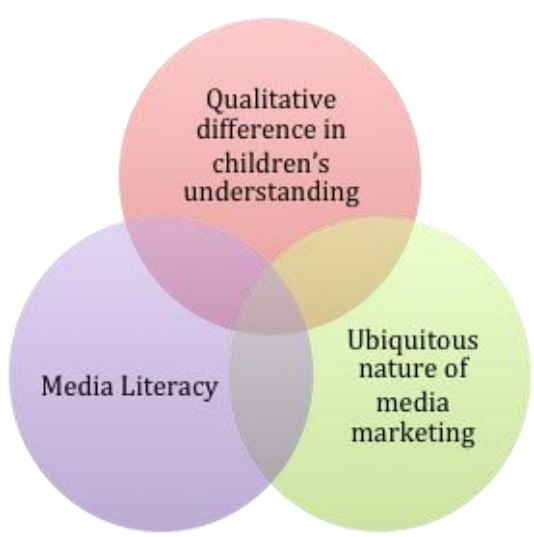

Figure 1. Significance of topic

This dissertation study aims to investigate this issue through an examination of the relationship between electronic and digital media content and children's theory of mind $[\mathrm{ToM}]$ and the developmental processes of media literacy acquisition. Theory of Mind [ToM] is the ability to understand the mental states and intentions of others and ourselves [1] [2] [3] [4]. If we consider that the 
development of a mature ToM enables individuals to explain, predict, and manage others' behaviours, and is considered to be an integral component for developing the ability to reason logically and abstractly, it seems both logical and plausible to consider it in relation to the necessary skills towards thinking critically about media [5].

\section{Literature Review}

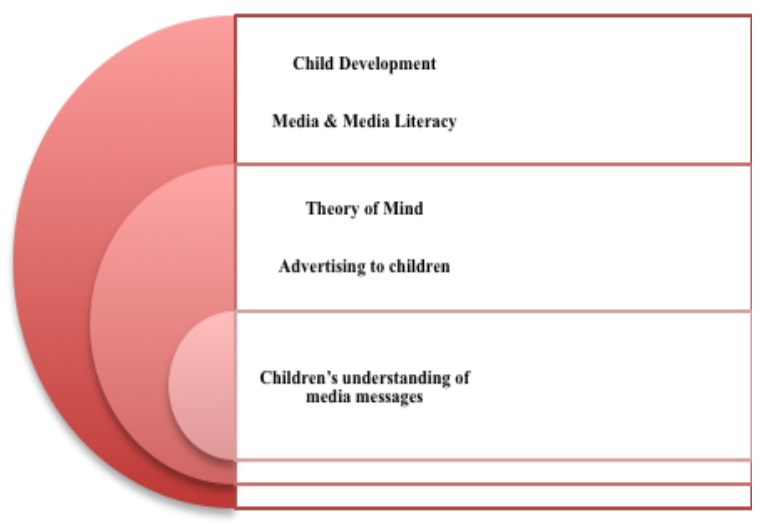

Figure 2. Literature review

\subsection{Child development}

Child development is shaped through everyday experiences, as proclaimed by John Dewey and Lev Vygotsky many decades ago. Today, however, what constitutes everyday experiences has taken on a whole new context for children within the Western world. This context is both mass media and personal media. Also changing is the thought that the more socially and culturally oriented of theories of Vygotsky and Bronfenbrenner, are considered to be increasingly beneficial in acknowledging that children's development is influenced by their environment and interactions within this environment, and does not "takes place in a vacuum" [11] [20].

Exposure to media is now a regular component of children's developmental experiences. In 2005, Roberts et al., found that children and youth, 8 to 18 years of age, spent $6 \frac{1}{2}$ hours a day using media. This figure is continuing to grow. In 2010, American children ages 8 and older were spending more than 7 hours a day with screen media [13]. Not only is screen time increasing, the media environ is also changing in terms of possibilities that have helped shift children's engagement with media from passive recipients of content, to active participants and co-creators of media content [14].

\subsection{Media \& media literacy}

Eco claimed that viewers must first be taught how to use television in order for television to teach them [15]. I propose that we can broaden this statement to include not only television, but also all media; and think about how we teach children to utilize media. According to Eco, children should learn about media and their role in critiquing and using media, prior to being educated with, or by, media [15]. In this way, teaching about media becomes more than a delivery of information. While the evaluation of online content may be portrayed as a required digital literacy skill, individuals need to move beyond assessing content based solely on its factual accuracy [16]. Beyond recognition of the relevance and authoritative or non-authoritative legitimacy of sites, digital literacy must include increased awareness of the persuasive components of media and the emotional dimensions that contribute to our use and interpretation [16] [17].

Currently, there are four broad conceptual aspects that are generally regarded as essential components of media literacy: representation, language, production, and audience [17]. In achieving media literacy, one must be able to perceive how messages are portrayed through media. Even though media often appears 'real', "digital media represent the world, rather than simply reflect it; offering particular interpretations and selections of reality, which inevitably embody implicit values and ideologies" [17]. In addition to being able to use language, the media literate individual must also understand how language works. The production component of literacy involves understanding the intent of the communicator; it is perceived that higher-order theory of mind abilities could be linked to this understanding [4] [17]. Finally, children must understand their stance as audience and realize they are being targeted by advertisers [17]. Children's ecological experiences could also play a part in this awareness.

\subsection{Theory of Mind [ToM]}

Theory of Mind [ToM] refers to this ability to understand the mental states and intentions of others [2]. Once mature, it enables individuals to explain, predict, and manage others' behaviours, and is considered to be an integral component for developing the ability to reason logically and abstractly [5]. It appears at about age 3, but is not mature until young adulthood [18]. Furthermore, Gunter, B., Oates, C., Blades, M. propose that "children do not interact with advertisements in the same way that they interact with other people and this may be another reason to expect children's full understanding of advertisements to lag in behind 
their understanding of minds and beliefs in other domains" [19].

It has been argued that ToM is likely more biologically, rather than socially based since it develops without specific teaching [3]. There is evidence, however, that a number of factors in the child's environment influence and enhance its development [20]. If children are able to apply ToM abilities to electronic tasks, it could equally be associated with required competencies for media literacy. While Wimmer \& Perner state that the format of the false belief task does not alter the child's ability, I propose that digital and/or electronic forms could influence children's understandings of false belief tasks.

Children need to understand the meaning behind language and the interpretations these meanings have for each of us, as consumers. They must learn the tools they need to think critically in response to television advertising because "language is a powerful tool for conveying ideas when it is used carefully, but when it is used poorly it makes good thinking difficult" [21]. Media literacy curricula must help children think critically for themselves, because if not, the media will think for them.

\subsection{Advertising to children}

Each year, billions of dollars are spent on advertising that is specifically targeted at children. This statement, coupled with Buckingham's claim that the media intervene and filter what they provide their audiences with, and the fact that they carefully play with words, images, and sounds to lead us into the world, as they want us to see it, is troublesome on so many levels [23]. From an early age, children learn to believe 'pink is for girls' and 'trucks are for boys', as well as particular cereal brands being, for example, 'good for sports' (Kellogg's Frosted Flakes). Advertising is one of the powerful means for the dissemination of such messages.

During the past thirty years, societal beliefs have shifted from the protection of children from media and commercial exploitation, by limiting advertising during children's programming, to allowing children to fully enter the marketplace and become child consumers [8]. This shift in belief transpired without a clear understanding of children's ability to interpret and engage critically with mass media content, thus creating possible implications for their overall health and well-being. As researchers, we need to move beyond a positioning of whether media is bad vs. good, and focus on a better understanding of media.

\subsection{Children's understanding of media}

There is controversy surrounding children's susceptibility to media influences [20]. Contrary to Buckingham's claim that children are not more influenced by media than adults, I suggest that they are more vulnerable, due in part to the qualitative differences in their understanding. "Children think differently from adults and there are qualitative differences in the way children of different ages understand the world around them"; a world, today, that greatly encompasses media [22]. Researchers must therefore attain a better grasp of children's ability to understand media, so that educators can ensure media literacy curricula that meet their understandings.

\section{Methodology}

Acknowledging that children are active participants in their own development, which is also influenced over time by broader social and cultural forces; children's development can thus be viewed as a co-constructive process [24]. Each child is unique and research with children must resist researching 'the child' and replace this discourse with the understanding that "children encounter their worlds in an individual and idiosyncratic manner and that their worlds are themselves all different" [25]. Similarly, Bronfenbrenner claimed that experience encompasses not only the objective properties of the environment, but also how these properties are perceived by the individual within that environment [11]. And so, the question becomes, how do children make sense of the media? To gain insight into their understanding of media, a constructivist ontological position, will frame the belief that the social reality of children is continually being accomplished by social actors, thus making their voice essential to research.

This study in progress will employ a developmental approach that will focus on sociocognitive theory and will uncover how children of different ages understand media content through an examination of theory of mind and Bronfenbrenner's ecological systems theory [11]. This philosophical and theoretical framework will both contextualize current understandings of child development, within its new relation to digital and electronic media forms, and examine whether previous developmental understandings stand true.

Bronfenbrenner has argued that individual understandings and actions are nested within family, social and cultural systems [11]. According to Bronfenbrenner and Morris, particular forms of interaction between an individual and its environment, including interactions with objects and symbols, known as proximal processes are inherent 
in development. Their form, power, content, and direction vary in relation to the individual's personal characteristics, immediate and remote environment, type of developmental outcome, and social changes occurring over the course of the individual's life.

An analysis of children's theory of mind from a theoretical perspective will identify how micro-, exo, and macro- systems inter-relate in children's interpretation of marketing messages. For, according to Bronfenbrenner and Morris, researchers must identify individual characteristics that are involved in child agency, such as beliefs, energy level, temperament, goals and motivation, since each of these 'force' characteristics impact not only how the individual experiences a situation, but the types of situations s/he seeks out. In doing so, this analysis will provides a unique contribution to the study of children's media literacy understandings, as it centralizes the socio-cultural nature of development rather than individualizing it as is most common within psychological studies of development.

In today's media savvy society, it is more crucial than ever to examine child development within the many different systems that influence its growth. Bronfenbrenner's ecological systems theory bursts the bubble of reality and allows for increased understanding of development that does not occur within a silo, or vacuum, as he refers to it; but is rather embedded and expressed within contextual environments [11]. Media has become increasingly pervasive within environmental contexts making an ecological approach to understanding children's development critical.

While the world has become increasingly mediated during the last decade; already in the 1970s Bronfenbrenner saw the pervasiveness of the media and its impact on family life [11]. Television has, and continues to have, an impact on society. Within the limited scope of media in the 1970s, Bronfenbrenner explained the influential role of television and considers its programming to be a part of the child's exosystem since it entered the home from an external source [11]. He argued that media had an indirect influence on parents and their interactions with their children and as such represented a second-order effect, not completely within the microsystem but across borders as an exosystem phenomenon, demonstrating the relationships within the different structural levels. Likewise, Strasburger, Wilson \& Jordan have encouraged questioning of the family system's role in understanding media for according to systems theory, media must be seen as a part of the complexity of families' lives, rather than an isolate entity [27]. Johnson further proposed a newly created ecological techno-microsystem that situates the developing child within the context of home, school, and community Internet use [28]. He proposed this system is needed in understanding children's Internet usage, due to the rise in digital technologies within their direct environment and the blurring boundaries of television and Internet content. With the many relations occurring amongst and between the ecological systems, the divides are continually getting lost as mass media entrenches the many facets of our lives. Increasingly, children and adults alike are less present solely within one structure of their environment; and the structures are blurred in a unifying way through the powers of media.

According to Darling, Bronfenbrenner's work leads to exploring development through three domains - the active person, its phenomenological nature, and ecological niches [29]. The person is therefore active in their development and both responds and reacts to the environment; the phenomenological nature of these responses and reactions is related to how one defines situations since the definition of a situation as real, results in real consequences; and thirdly, we must acknowledge the uniqueness of each environment and the fact that each individual will respond to the environment in different ways [29]. It therefore becomes essential, when examining children's understanding of marketing messages, to gain insight into both their responses and reactions to these messages in their everyday emotions and actions.

The examination of Theory of Mind [ToM] will provide a basic understanding of the participating children's level of ToM ability in understanding the mental states and intentions of others and ourselves as shown by Premack \& Woodruff, Doherty, Astington \& Edward, Miller [1] [2] [3] [4]. Children's understanding of media will then be examined using narrative questions that will ask children to apply their ToM abilities in demonstrating their understanding of the intent and beliefs (their own and others) regarding advertising.

Lemish alludes that a qualitative approach would typically not unveil meaningful information from the mapping of children's online activities [30]. However, I suggest that within a mixed-methods approach, a collection of information from parents regarding their children's ecological contexts, such as time spent engaged in electronic and media activities, will further assist the qualitative examination of how children's ToM understandings, and media understandings are contextualized within micro-, exo-, and macro-ecological systems.

\subsection{Hypothesis}

An examination of how children 7-9 years of age understand media messages will provide insight into the qualitative differences in children's cognitive developmental abilities. If we consider that the 
development of a mature theory of mind enables individuals to explain, predict, and manage others' behaviours, and is considered to be an integral component for developing the ability to reason logically and abstractly, it seems both logical and plausible to consider it in relation to the necessary skills towards thinking critically about media [5].

My research question is operationally defined as three individual, yet interrelated, questions.

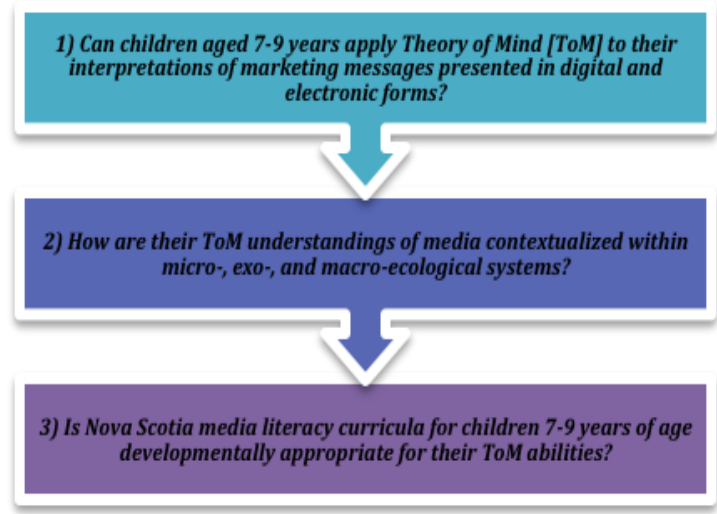

Figure 3. Research questions

It is hypothesized that by examining children's ToM ability utilizing a TOM Test and comparing these results to similar ToM Tasks in relation to digital and electronic media marketing forms, a comparative analysis will show evidence of possible discrepancies in ability [31]. While children ages 79 years of age will likely demonstrate some degree of theory of mind ability, it is hypothesized that they will not be able to apply ToM to interpret and engage critically with electronic and digital media forms.

3.1.1. Independent Variables. The same TOM Test tasks and interview questions will be utilized with each participant.

3.1.2. Dependent Variables. It is proposed that children's potential lack of ToM ability in relation to electronic forms will result in children's lack of understanding of the intent of advertising.

3.1.3 Controlled variables. All children will be ages 7-9, residing in the same geographical region, and able to speak English fluently.

In an effort to account for known variables in the child's ecological system, a parent questionnaire/interview will provide insight into factors within the child's microsystem that may contribute to their understanding of media.

\section{Research design}

A three-stage research mixed-methods design will be utilized to address each of the research questions and emphasize each child's ToM ability in relation to media literacy. Television ads that could also be found on YouTube were chosen since it was found that while there is a gradual shift towards online viewing or mobile device content amongst children and teens, they still spend the majority of their time watching television.

\subsection{Method of data collection}

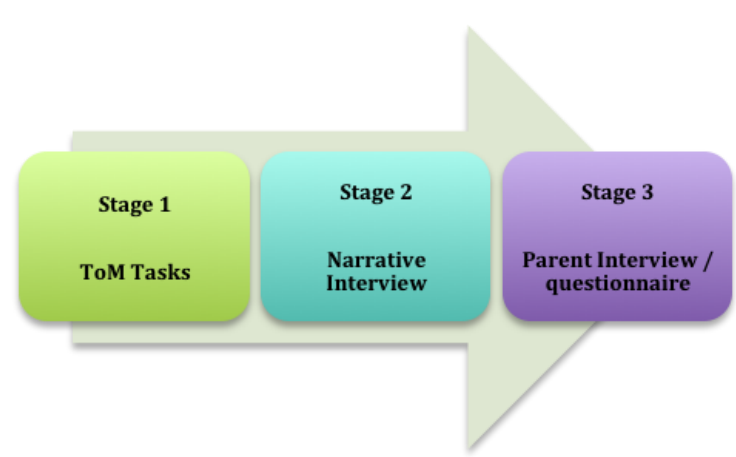

Figure 4. Data collection stages

In valuing a qualitative research method, one-onone discussions will enable each child's expressed understanding of media to be heard; for, as described by Lemish, true meaning is constructed by the child who experiences it [30]. It is therefore essential to capture the voice of the child so that we can begin to see the media world through their eyes, and gain insight into their ToM understandings. Their voice becomes evidence for researchers' interpretation and analysis. Throughout the interview process, I will ensure a participatory approach that will aim to disperse this power amongst the participants.

\subsection{Stage one}

Stage One will explore children's ability to understand the intended communication meanings of others of their own age and/or of adults. Children will be presented with a brief scenario and asked to answer questions that aim to capture their understanding. These scenarios were specifically chosen due to the more advanced aspects of theory of mind that are required in completing these tasks, such as second-order belief and understanding of humour. Responses will later be analyzed in terms of varying ToM abilities. All children will be asked to continue to Stage Two of the study. 


\subsection{Stage two}

Stage Two will explore children's ability to understand the intended meanings of electronic and digital marketing communications. As a pre-activity children will be invited to discuss their favourite media activity. This will engage the children in conversation and provide a comfortable venue for the discussion to follow. Children will be invited to view the Oreo Canada Wonderfilled Hockey Dream 2014 advertisement video clip, and will participate in the corresponding narrative open-ended interview questions. This particular video clip was chosen because of its digital animation and its portrayal of how advertisers today are often trying to get consumers to buy into an experience, and then the product by association. In this case, rather than speaking of the deliciousness of the cookie, children (and adults) can link the cookie to emotions and the dream of being an NHL hockey player. It is anticipated that this type of advertisement will provide a means towards rich discussions with participants regarding their understanding of marketing messages.

Children will then be shown 4 still frame product images of advertisements commonly aired during children's television programming and easily accessible on the Internet, Easy Bake Oven, Lego, Fruitloops, and Super Mario 3D World. They will then comment on which of these 4 products they are most familiar with, by answering the following questions: "Do you have any of these items, or know about them?" "Are any of these your favourite?" If yes: "Why is it your favourite?" and "Have you seen ads for these items?". The researcher will then direct the children to pick one of the ads to look at online, preferably the one they are most familiar with. Children will be invited to view the corresponding video clip advertisement that will include either real persons, digitally animated characters, or complete digital animation. Exploration of children's understandings will consist of semi-structured narrative interviews that ask children to explain what they understand to be the meaning of the transmitted messages. The questions are framed to seek children's ability in identifying other people's beliefs and intent, which may also differ from their own; common questions relating to theory of mind development.

Stage One and Two of the study will be conducted in one session to minimize possible variables. A 1 hour time slot will be allotted for each interview.

\subsection{Stage three}

Immediately following Stage Two, information on children's micro-ecological contexts will be collected from the children's parents. The researcher will collect the completed parent questionnaire and engage in a brief interview with the participating parent. Data collected will include time spent engaged in electronic and media activities, individual and family demographics, child temperament, and experience with media literacy activities.

\subsection{Participants}

Ten participants and their parent(s) will be selected from the neighbouring communities of Margaree and Cheticamp, within Nova Scotia, Canada. This catchment area was chosen due to its proximity to the researcher. The mother-tongue of the chosen participants will preferably be English, however, it is likely that most participants will be bilingual. Participants who are fluent in English will be considered for the study. These two small rural communities also provide a similar contextual framework. It is anticipated that the chosen sample size will provide sufficient depth and scope to allow for rich contextual analysis.

\subsection{Method of data analysis}

A qualitative data analysis between children's ToM abilities, their expressed understanding of media messages, and information on their microecological context will be conducted. Children's understandings of the meanings of the transmitted messages from Stage Two will be analyzed in relation to normative expectations of the children's ToM abilities and compared to their responses in Stage One. The exo- and macro- contexts of the participants will be investigated for evidence of social and cultural components that could have influenced their understanding.

A content analysis of the goals and procedures of existing Nova Scotia curricula for the ages identified will be undertaken and the data will be analyzed in terms of their match with the findings of from Stage Two and Stage Three of the study, acknowledging children's ToM abilities in relation to media marketing messages and the inherent contextual factors. Findings will be utilized in a way that best meets the needs of the participants; that is, in ensuring that media literacy curricula within Nova Scotia is developmentally appropriate for Nova Scotia's students.

\section{Implications for research}

Through an examination of the contextual relationship between Theory of Mind and media literacy, this innovative research study will, 
1) Provide a unique contribution to understanding children's developmental abilities in relation to media marketing messages;

2) Centralize the socio-cultural nature of ToM development in relation to media understandings;

3) provide a developmental basis for exploring the appropriateness of school-age media literacy curricula.

The media is constantly evolving and "decisions made in the next few years - by the industry and policy-makers - will have a far-reaching impact on how the twenty-first century media system socializes young people into two key roles - as citizens and as consumers" [14]. Now, more than ever, we need to understand how children make sense of media.

For contemporary children, one of the primary social and cultural influences on their lives is that of electronic and digital media and the marketing messages that they disseminate. In adherence with Bronfenbrenner who has argued that individual understandings and actions are nested within family, social and cultural systems, I suggest that my findings will provide insight for those within family, social and cultural systems [11]. Parents will gain insight on their child's media exposure, and how they can provide media literacy approaches to mass media with their child. This research will also shed light on children's developmental abilities in terms of ToM, so that educators can design literacy strategies that match and extend children's ability to understand the thoughts and messages transmitted through media; and policy makers will be able to adopt media literate approaches to learning.

Children need to be provided with the tools required to be media literate so that they can better understand media messaged, because we are not always going to be with them as they attempt to decipher the spoken or written pervasive texts that they will encounter daily, and often don't notice, and the societal messages they convey. As a result, without developmentally appropriate media literacy, children can be enticed into believing what the advertiser wants them to believe.

\section{References}

[1] Premack, D., \& Woodruff, G. (1978). Does the chimpanzee have a 'theory of mind'? Behavioral and Brain Sciences, 4, 515-526.

[2] Doherty, M. J. (2009). Theory of mind. New York, NY: Psychology Press.

[3] Astington, J. W., \& Edward, M. J. (2010). The development of theory of mind in early childhood. In R. E. Tremblay, M. Boivin, R. DeV. Peters (Eds.). Encyclopedia on early childhood development. Centre of Excellence for Early Childhood Development.
[4] Miller, S.A. (2012). Theory of mind beyond the preschool years. New York, NY: Taylor \& Francis Group, LLC.

[5] Frye, D., \& Moore, C. (Eds.). (1991). Children's theories of mind: Mental states and social understanding. Hillsdale, NJ: Lawrence Erlbaum Associates, Inc.

[6] Comstock, G., \& Scharrer, F. (1999). Television: What's on, who's watching, and what it means. San Diego, CA: Academic Press. Retrieved from http://pediatrics,aappublications.org/content/118/6/2563.f ull

[7] Batada, A., \& Borzekowski, D. (2008). Snap, crackle, what? Journal of Children and Media, 2(1), 19-36.

[8] McDonnell, K. (2001). Honey, we lost the kids: Rethinking childhood in the multimedia age. Toronto, ON: Second Story Press.

[9] Henry, H. K. M. \& Borzekowski, D. L. G. (2011). The nag factor: A mixed-methodology study in the US of young children's requests for advertised products. Journal of Children and Media, 5(3), 298-317.

[10] Common Sense Media (2014). Advertising to children and teens: Current practices. San Francisco, CA: Common Sense Media.

[11] Bronfenbrenner, U. (1979). The ecology of human development. Cambridge, MA: Harvard University Press.

[12] Roberts et al. Roberts, D. F., Foehr, U. G., \& Rideout, V. (2005). Generation M: Media in the lives of 8-18 year olds. Menlo Park, CA: Henry J. Kaiser Family Foundation.

[13] Rideout, V. J., Foehr, U. G., \& Roberts, D. F. (2010). Generation m2: Media in the lives of 8-to 18-year olds. Menlo Park: Kaiser Family Foundation. Retrieved from http://files.eric.ed.gov/fulltext/ED527859.pdf

[14] Montgomery, K. C. (2011). Balancing the needs of young people in the digital marketplace. Journal of Children and Media, 5(3), 334-337.

[15] Eco, U. (1979). Can television teach? Screen Education, 31, 15-24.

[16] Livingstone, S., van Couverin, E. \& Thumin, N. (2005). Adult media literacy: A review of the research literature. London, UK: Ofcom.

[17] Buckingham, D. (2008). Defining digital literacy. In C. Lankshear, \& M. Knobel (Eds). Digital literacies: Concepts, policies, \& practices (pp. 73-90). New York, NY: Peter Lang.

[18] Wellman, H. M., Cross, D., \& Watson, J. (2001). Meta-analysis of theory-of-mind: The truth about false belief. Child Development, 72(3), 655-684.

[19] Gunter, B., Oates, C., \& Blades, M. (2005). Advertising to children on TV. Mahwah, NJ: Lawrence Erlbaum Associates, Inc. 
[20] Livingstone, S. (2007). Do the media harm children? Journal of Children and Media, 1(1), 5-14.

[21] Ozmon, H. A. (2012). Philosophical foundations of education (9th ed.). Upper Saddle River, NJ: Pearson Education Inc.

[22] Greig, A., \& Taylor, J. (1999). Doing research with children. Thousand Oaks, CA: Sage Publications.

[23] Buckingham, D. (2003). Media education: Literacy, learning and contemporary culture. Cambridge, UK: Polity Press.

[24] Valsiner, J., Branco, A.U., \& Dantas, C.M. (1997). Co-construction of human development: heterogeneity within parental belief orientations. In J.E. Grusec \& L. Kuczynski (Eds.), Parenting and children's internalization of values: A handbook of contemporary theory (pp. 283-304). New York, NY: Wiley.

[25] Green, S, \& Hill, M. (2005). Researching children's experiences: Methods and methodological issues. In S. Green, \& D. Hogan (Eds.), Researching children's experience (pp.1-21). Thousand Oaks, CA: Sage Publications Ltd.

[26] Bronfenbrenner, U. \& Morris, P. A. (2006). The bioecological model of human development. In W. Damon (Editor-in Chief \& R. M. Lerner, (Vol. Ed.), Handbook of child psychology, Vol. 1, 6th ed. New York, NY: Wiley.

[27] Strasburger, V. C., Wilson, B.J., \& Jordan, A. B. (2009). Children, adolescents, and the media (2nd ed.). Thousand Oaks, CA: Sage Publications, Inc.

[28] Johnson, G. M. (2010). Internet use and child development: The techno-microsystem. Australian Journal of Educational \& Developmental Psychology, 10, $32-43$.

[29] Darling, N. (2007). Ecological systems theory: The person in the center of the circles. Research in Human Development, 4(3-4), 203-217.

[30] Lemish, D., (2007). How do researchers study young people and the media? In S. R. Mazzarella (Ed.), 20 Questions about youth \& the media (pp.73-86). New York, NY: Peter Lang.

[31] Muris, P., Steerneman, P., Meesters, C., Mercklebach, H., Horselenberg, R., van den Hogen, T., \& van Dongen, L. (1999). The TOM Test: A new instrument for assessing theory of mind in normal children and children with pervasive developmental disorders. Journal of Autism and Developmental Disorders, 29(1), 67-78. 